\title{
Fast Axonal Transport of Modulatory Neuropeptides from Central Ganglia to Components of the Feeding System in Aplysia
}

\author{
Philip E. Lloyd \\ Department of Pharmacological and Physiological Sciences and Committee on Neurobiology, The University of Chicago, \\ Chicago, Illinois 60637
}

\begin{abstract}
The transport of neuropeptides from central ganglia to components of the feeding system was studied in Aplysia. Peptide transport was determined by incubating buccal or cerebral ganglia with ${ }^{35} \mathrm{~S}-$ methionine and measuring the appearance of labeled peptides by high-pressure liquid chromatography (HPLC) of extracts of target tissues. Selected nerves were left intact and passed through a Vaseline diffusion barrier separating the ganglia and their targets. Five major labeled peptides were observed to be transported from the buccal ganglia to feeding muscles. They were buccalin, FMRFamide, myomodulin, and 2 small cardioactive peptides. Each of these peptides has been shown to modulate the responses of these muscles to their motor neurons. The peptides were transported by fast axonal transport, as judged by the distance transported and the sensitivity to colchicine. When normalized to correct for differences in total incorporation, the patterns of peptide transport were reproducible between animals. The nature and amount of the peptides transported were different for different muscles. The nature of peptide transport also varied for different nerve groups. These results support the proposition that these $\mathbf{5}$ peptides act as modulatory transmitters at feeding muscles. No transport of neuropeptides from the cerebral ganglia to feeding muscles was observed, although myomodulin was specifically transported to the buccal ganglia. This suggests that this peptide may play an important role in the previously observed regulation of buccal ganglia activity by neurons in the cerebral ganglla.
\end{abstract}

The sequences of a number of neuropeptides of Aplysia have been determined. These peptides were generally chosen for study because of some specific property. For example, they may be synthesized in large quantities, either in very large individual neurons or in homogeneous cell groups. Such peptides are amenable to sequencing either through molecular genetic approaches or through conventional protein-sequencing procedures (Scheller ct al., 1984). However, many physiologically important neuropeptides may not fall into this category and therefore resist identification. More general approaches to peptide identification

\footnotetext{
Received Nov. 13, 1987; revised Jan. 21, 1988; accepted Jan. 22, 1988

I thank C. Connolly for expert assistance, K. R. Weiss for gifts of synthetic Bn and $\mathrm{Mm}$, and $\mathrm{W}$. Pearson for critical reading of the manuscript. This work was supported by NIH Grant NS 23569 and a Whitehall grant.

Correspondence should be addressed to Philip E. Lloyd, Department of Pharmacological and Physiological Sciences and Committee on Neurobiology, The University of Chicago, 947 East 58th, Chicago, IL 60637.

Copyright (C) 1988 Society for Neuroscience $0270-6474 / 88 / 093507-08 \$ 02.00 / 0$
}

may reveal the existence of these peptides. The approach pursued in the present study was to identify neuropeptides that were labeled in central ganglia and transported by fast axonal transport to target muscles or ganglia.

The system chosen for this study consists of the buccal and cerebral ganglia and the muscles of the buccal mass. This comprises the consummatory part of the feeding apparatus of Aplysia and has been extensively studied at a number of levels. Neurons in the buccal ganglia generate the cyclic feeding motor output that drives biting and swallowing movements of muscles of the buccal mass (Gardner, 1971; Kupfermann, 1974). Neurons in the cerebral ganglia control the output of the buccal ganglia and modulate peripheral neuromuscular synapses (Weiss et al., 1978).

Only peptides that contain methionine residues were studied. The results indicate that at least 5 methionine-containing peptides are transported from the buccal ganglia to the buccal muscle. These peptides were identified as myomodulin (Mm; Cropper et al., 1987b), the 2 small cardioactive peptides (SCP $\mathbf{A}_{\mathrm{A}}$; Lloyd et al., 1987b; and $\mathrm{SCP}_{\mathrm{B}}$; Morris et al., 1982), FMRFamide (Fa; Price and Greenberg, 1977), and buccalin (Bn; Cropper et al., $1987 \mathrm{c}$ ). Each of the 5 peptides has been shown to modulate the efficacy of motor neurons in producing buccal muscle contractions. In muscle I5 (also termed the accessory radula closer muscle; ARC), the SCPs and Mm enhance, while $\mathrm{Bn}$ and Fa decrease, the amplitude of contractions produced by stimulation of motor neurons (Lloyd et al., 1984; Weiss et al., 1986; Cropper et al., $1987 \mathrm{~b}, \mathrm{c})$. Both the nature of the modulation and the mechanisms underlying it vary for different buccal muscles. For example, the SCPs and Fa both enhance contractions of an extrinsic buccal muscle (Richmond et al., 1986), and the SCPs have been shown to enhance contractions of another intrinsic muscle, but by a different mechanism than in I5 (D. P. Lotshaw and $P$. E. Lloyd, unpublished observations). Likewise, the transport of peptides to individual buccal muscles is not uniform. Different muscle groups receive different complements of peptides, and particular peptides are preferentially routed down particular nerve groups. These results should aid attempts both to understand the nature of modulation at individual buccal muscles and to identify neurons that synthesize the peptides.

The cerebral ganglia are the other central ganglia involved in generating aspects of feeding behavior (Kupfermann, 1974). No measurable transport of peptides from the cerebral ganglia to buccal muscle was observed. This was somewhat surprising, as the major nonpeptidergic modulators of buccal muscles are serotonergic neurons in the cerebral ganglia (Weiss et al., 1978). However, selective transport of $\mathrm{Mm}$ from the cerebral to the buccal ganglia was observed. This suggests that this peptide may have important central actions in the buccal ganglia. 


\section{Materials and Methods}

\section{Animals}

Aplysia californica (Marinus; 150-250 gm) were kept in running seawater tanks at $15^{\circ} \mathrm{C}$ and fed seaweed (laver; 0.5 gm dry weight) every 3-4 d. Animals were immobilized with an injection of isotonic $\mathrm{MgCl}_{2}$ equal to $25 \%$ of their body weight, and the cerebral ganglia, buccal ganglia, and buccal mass removed.

\section{Transport experiments}

Labeled buccal ganglia. The cerebral-buccal connectives (CBCs) were cut and the cerebral ganglia discarded. The buccal nerves to be tested were protected from mechanical damage, while the other buccal nerves were severed. The ganglia-buccal mass complex was then placed in transport dishes containing $25 \%$ isotonic $\mathrm{MgCl}_{2}: 75 \%$ artificial seawater (ASW: $460 \mathrm{~mm} \mathrm{NaCl}, 10 \mathrm{~mm} \mathrm{KCl}, 11 \mathrm{~mm} \mathrm{CaCl}, 55 \mathrm{~mm} \mathrm{MgCl}, 5 \mathrm{~mm}$ $\mathrm{NaHCO}_{3}, \mathrm{pH} 7.8$ ). The transport dishes were $150 \mathrm{ml}$ in volume and had Sylgard bases into which polypropylene cylinders ( $12 \mathrm{~mm}$ diameter) were imbedded. The vertical cylinders were $2.5 \mathrm{~cm}$ high, filled with Sylgard for $1.8 \mathrm{~cm}$, and had $1-\mathrm{mm}$-wide vertical slits to allow passage of the nerves. The slits were occluded with Vaseline and the buccal ganglia pinned in the inner chamber at the top of the tube, with the nerves to be tested running through the Vaseline gap. Extra Vaseline was added to the gap to reseal it after placing the nerves through it. The solution in the large outside chamber was then changed to one with the following composition: $25 \%$ Aplysia blood, $75 \%$ ASW, $0.01 \%$ glucose, antibiotics (penicillin, $25 \mathrm{U} / \mathrm{ml}$; streptomycin, $25 \mu \mathrm{g} / \mathrm{ml}$ ), $0.01 \% 2$-mercaptoethanol, and $100 \mu \mathrm{M}$ cold methionine. The inside chamber was changed to the following solution: $50 \%$ Aplysia blood, $50 \%$ ASW, $0.01 \%$ glucose, antibiotics, $0.01 \% 2$-mercaptoethanol, and $0.5 \mathrm{mCi} / \mathrm{ml}{ }^{35} \mathrm{~S}$ methionine (Amersham; stabilized with $0.1 \% 2$-mercaptoethanol and $15 \mathrm{~mm}$ pyridine 3,4 dicarboxylic acid). After a $24 \mathrm{hr}$ labeling period at $15^{\circ} \mathrm{C}$, the solutions in both inner and outer chambers were replaced with a chase solution consisting of ASW, $0.01 \%$ glucose, antibiotics, $0.01 \% 2$-mercaptoethanol, and $1 \mathrm{~mm}$ methionine. All solutions were sterilized $(0.2-\mu m-f i l t e r e d)$ immediately prior to use. For the chase, the solution in the inner chamber was turned over $\sim 20 \times$, while the solution in the outer chamber was turned over twice over a period of $2 \mathrm{hr}$. Initially, chase periods of 24 or $48 \mathrm{hr}$ were used; however, as no differences in transport were observed between the 2 durations, $24 \mathrm{hr}$ chase periods were then routinely used.

Radioactivity in the inner and outer chambers was monitored by liquid scintillation counting of small aliquots performed at the end of the label period and occasionally at the end of the chase periods as well. At the end of the label periods, the ratio of $\mathrm{cpm} / \mathrm{ml}$ in the inner : outer chamber was $1953 \pm 717(\mathrm{SE})$ for 18 preparations. In the 10 preparations for which measurements were made at the end of the chase periods, the ratio was $1197 \pm 566$. In several experiments, $10 \mathrm{~mm}$ colchicine (Sigma) was added to both the inner and outer chambers throughout the label and chase periods.

Labeled cerebral ganglia. Labeling was carried out exactly as described for the buccal ganglia, except that the CBCs were not cut, the cerebral ganglia were placed in the inner chamber, and the paired CBC's were run through the Vaseline gap to the buccal ganglia and buccal mass in the outer chamber. All buccal nerves except the esophageal and salivary nerves remained intact.

\section{Buccal muscle designations}

Transport to individual muscles or muscle groups was analyzed. Muscles were identified using the original designations of Howells (1942). In some cases, it was difficult to be certain of the assignments. For this reason, Figure 1 shows the muscle designations used in the present study, with the buccal mass pinned out in a manner similar to that used during the dissections.

\section{Analyses of ${ }^{35} S$-methionine-labeled peptides in buccal ganglia and muscle}

At the end of the chase periods, the remaining intact buccal nerves were cut, and the buccal mass removed and dissected in $25 \%$ isotonic $\mathrm{MgCl}_{2}$ $75 \%$ ASW. A longitudinal incision was made along the dorsal midline from the mouth opening to the esophageal opening, and the mass pinned

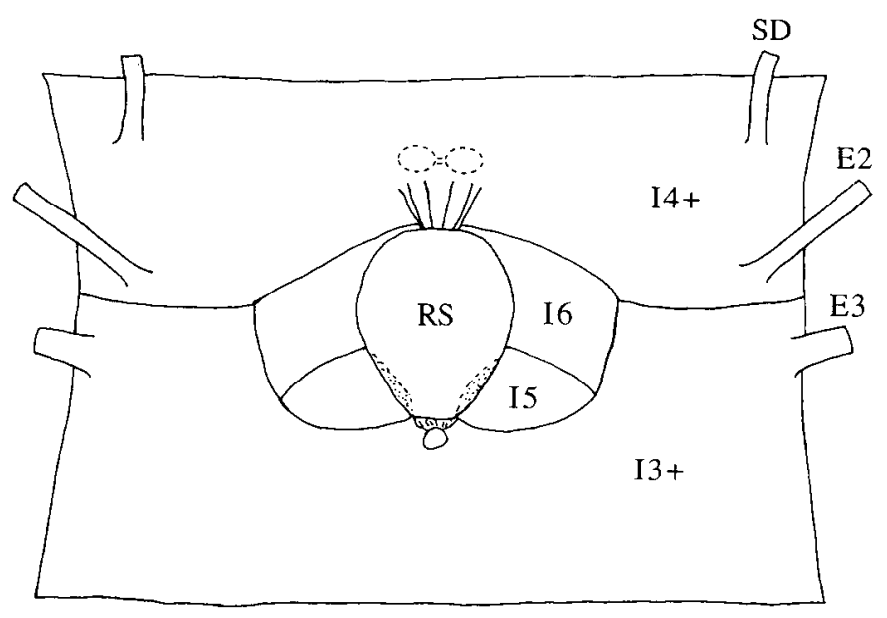

Figure 1. Morphology of the buccal mass, showing the major muscles and muscle groups. A dorsal midline incision was placed between the paired extrinsic $(E)$ muscles E1 and E3 and the spherical mass pinned flat with the ventral side facing upward. The original position of the buccal ganglia is indicated by the paired dashed circles. Muscle designations were modified from Howells (1942). The thin intrinsic (I) muscle, I2, has been removed to expose the I5 and I6 muscles. The I3 muscle is covered with a thin muscle band termed I1 by Howells; however, this muscle is extensively interconnected with the much thicker I 3 , and was always dissected with $\mathrm{I} 3$ and the 2 muscles termed I3+. The designation I4+ was used for muscle I4 plus the connective tissue that remained after the removal of all the intrinsic muscles. Extrinsic muscles E1, which run from just below I5 to the body wall near the mouth, are not shown in this diagram. A buccal mass from a $200 \mathrm{gm}$ animal dissected as shown would be $2 \times 3 \mathrm{~cm}$. $R S$, radula sac; $S D$, salivary duct.

flat, with the radula sac facing upward in the middle of the preparation (see Fig. 1). Muscles were dissected from the innervated side and symmetrical muscles from the noninnervated side to act as controls. Muscles were blotted, weighed, and placed in homogenizers containing $0.02 \mathrm{M}$ trifluoroacetic acid (TFA) and heated to $100^{\circ} \mathrm{C}$ for $10 \mathrm{~min}$. The TFA solution was spiked with $10^{-5} \mathrm{M} \mathrm{Fa}, \mathrm{SCP}_{\mathrm{A}}$, and $\mathrm{SCP}_{\mathrm{B}}$ (Peninsula). A tissue solution of $100 \mathrm{mg}$ (wt/vol) tissue $/ 1 \mathrm{ml}(\mathrm{wt} / \mathrm{vol}) 0.02 \mathrm{M}$ TFA, with a minimum volume of $500 \mu \mathrm{l}$ for tissue weights less than $50 \mathrm{mg}$, was used. After cooling, the tissue was homogenized, centrifuged at $10,000 \times g$ for $10 \mathrm{~min}$, and the supernatant filtered on a Gelman LC13 $(0.45 \mu \mathrm{m})$ filter before HPLC.

HPLC was carried out on a $0.46 \times 22 \mathrm{~cm}$ Brownlee RP-300 C8 column with a guard column. The first mode of HPLC used $0.01 \mathrm{M}$ TFA as a counterion, and a gradient from $95 \% \mathrm{H}_{2} \mathrm{O}, 5 \% \mathrm{CH}_{3} \mathrm{CN}$ to $47 \% \mathrm{H}_{2} \mathrm{O}, 53 \% \mathrm{CH}_{3} \mathrm{CN}$ in $20 \mathrm{~min}$ at a flow rate of $2 \mathrm{ml} / \mathrm{min}$. Injections were $600 \mu \mathrm{l}$ of $0.02 \mathrm{M}$ TFA in $\mathrm{H}_{2} \mathrm{O}$. Aliquots of the samples from this run were counted, and the remainder of the samples of interest dried and run on the same column with $0.01 \mathrm{M}$ heptafluorobutyric acid (HFBA) replacing the TFA. The HFBA gradient was comprised of 3 linear segments with different slopes. The first segment was from $79 \% \mathrm{H}_{2} \mathrm{O}, 21 \%$ $\mathrm{CH}_{3} \mathrm{CN}$ to $76 \% \mathrm{H}_{2} \mathrm{O}, 24 \% \mathrm{CH}_{3} \mathrm{CN}$ in 2 min, followed by a segment from $76 \% \mathrm{H}_{2} \mathrm{O}, 24 \% \mathrm{CH}_{3} \mathrm{CN}$ to $72 \% \mathrm{H}_{2} \mathrm{O}, 28 \% \mathrm{CH}_{3} \mathrm{CN}$ in $12 \mathrm{~min}$. The final segment was from $72 \% \mathrm{H}_{2} \mathrm{O}, 28 \% \mathrm{CH}_{3} \mathrm{CN}$ to $65 \% \mathrm{H}_{2} \mathrm{O}, 35 \%$ $\mathrm{CH}_{3} \mathrm{CN}$. The flow rate was $2 \mathrm{ml} / \mathrm{min}$ and injections were $200 \mu \mathrm{l}$ of 0.02 M HFBA in $\mathrm{H}_{2} \mathrm{O}$. Entire samples from these runs were counted. Occasionally, a third HPLC method was used in addition to the previous 2 to confirm peptide identity. This method used the same column described above, but was carried out using $25 \mathrm{~mm}$ triethylamine acetate (TEAA) at pH 5.5 and a gradient from $90 \% \mathrm{H}_{2} \mathrm{O}, 10 \% \mathrm{CH}_{3} \mathrm{CN}$ to $55 \%$ $\mathrm{H}_{2} \mathrm{O}, 45 \% \mathrm{CH}_{3} \mathrm{CN}$ in $18 \mathrm{~min}$ at a flow rate of $2 \mathrm{ml} / \mathrm{min}$.

Radiolabeled materials with very short retention times on the Brownlee column were analyzed using a more retentive $0.5 \times 25 \mathrm{~cm}$ Isco C 8 $(5 \mu \mathrm{m})$ column. This column was run isocratically, either with $0.01 \mathrm{M}$ TFA and $98 \% \mathrm{H}_{2} \mathrm{O}, 2 \% \mathrm{CH}_{3} \mathrm{CN}$, or with $0.01 \mathrm{M} \mathrm{HFBA}$ and $93 \% \mathrm{H}_{2} \mathrm{O}$, $7 \% \mathrm{CH}_{3} \mathrm{CN}$. 

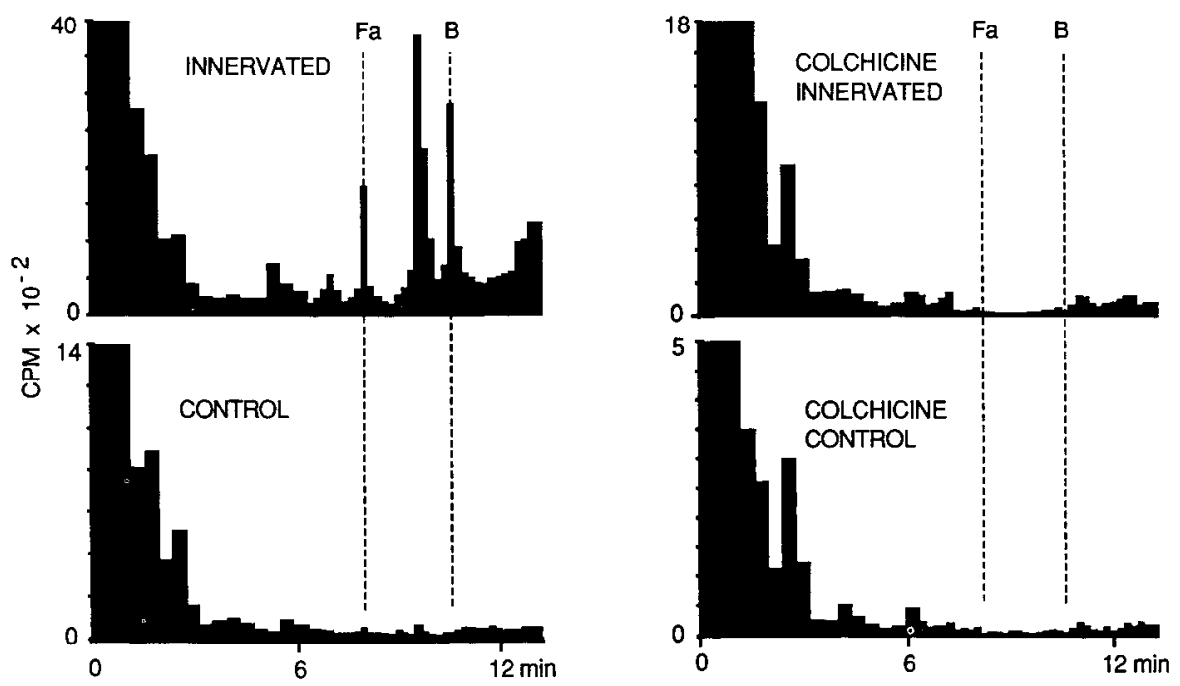

Figure 2. HPLC of extracts from buccal muscles indicates that the transport of neuropeptides from buccal ganglia to buccal muscles was completely blocked by colchicine. Transport with the lateral nerves intact on one side (INNERVATED) and cut on the other (CONTROL). The 2 preparations were run in parallel with all solutions in common, except that $10 \mathrm{~mm}$ colchicine was added to one of them. At the end of the experiment, the buccal mass was split at the midline and each half homogenized. The histograms are from a portion of the extracts equivalent to $50 \mathrm{mg}$ of buccal muscle. Cold synthetic peptides were added before homogenization and the positions of the $\mathrm{Fa}$ and $\mathrm{SCP}_{\mathrm{B}}$ absorbance peaks are indicated by the dashed lines. The peak of label between $\mathrm{Fa}$ and $\mathrm{SCP}_{\mathrm{B}}$ is comprised of 3 peptides: $\mathrm{Mm}, \mathrm{SCP}_{\mathrm{A}}$, and $\mathrm{Bn}$. Note that transport of methionine-containing neuropeptides only occurred when the preparation was innervated and colchicine was absent. In each experiment, the axes of the innervated and control sides were scaled to the total number of counts per minute collected in each run. There was always more label on the innervated sides, even in the presence of colchicine. This is especially true of label with short retention times.

\section{Results}

Fast axonal transport of methionine-labeled peptides from buccal ganglia to buccal muscle

Labeled peptide peaks were observed only in muscle extracts from the side of the buccal mass in which the innervation from the ganglia remained intact (Fig. 2). The 2 peaks of label corresponding to FMRFamide and $\mathrm{SCP}_{\mathrm{B}}$ are indicated in Figure 2. The larger peak of label between $\mathrm{Fa}$ and $\mathrm{SCP}_{\mathrm{B}}$ is composed of $\mathrm{Bn}, \mathrm{Mm}$, and $\mathrm{SCP}_{\mathrm{A}}$ (see below). This indicates that the peptides were transported from the ganglia to the muscles via the intact nerves and were not synthesized by the muscles themselves. It also demonstrates that this transport was confined to the side of the buccal mass with intact nerves. Thus, the peptides were not transported across the midline of the buccal mass. The nature of the transport to individual muscles or muscle groups is described below.

In the case of some of the more distal muscles, only $2 \mathrm{~d}$ were required for the synthesis, processing, and transport of the peptides over distances of several centimeters. It appears that this must occur via fast axonal transport. This was tested by determining the effects of $10 \mathrm{~mm}$ colchicine on peptide transport (Schwartz, 1979). Figure 2 shows the results of such an experiment performed using the lateral nerve group because the longer length of these nerves allowed them to be positioned through the Vaseline gap with less stretching (see below). Significant transport of peptides was observed in each of 5 experiments with this nerve group. In contrast, no peptide transport was observed in 2 experiments with the same nerve group in the presence of colchicine. In the experiment shown in Figure 2, peptide transport was analyzed from 3 preparations using all the same solutions, except that colchicine was added in 2 of the preparations. Colchicine did not appear to affect incorporation of methionine or processing to mature peptides. HPLC of buccal ganglia extracts at the end of the experiments indicated that there was more label in the $\mathrm{Fa}, \mathrm{Bn}-\mathrm{Mm}-\mathrm{SCP}_{\mathrm{A}}$, and $\mathrm{SCP}_{\mathrm{B}}$ peaks in the 2 colchicine-treated ganglia than in the untreated ganglia. The sensitivity to colchicine confirms that the peptides are transported from the ganglia to muscle by fast axonal transport.

\section{Diffusion of labeled methionine and glutathione}

Signiticantly more radioactivity was present in the unretained fractions from innervated muscles than noninnervated muscles (e.g., Fig. 2). This difference was not dependent on active transport because it was also observed in the presence of colchicine. The nature of the radioactivity in these samples was investigated by running them on a more retentive column. Most of the radioactivity was associated with unincorporated ${ }^{35} \mathrm{~S}$-methionine. Peaks with retention times similar to that of cysteine were also observed. A major peak that was predominantly in the innervated muscles was oxidized (disulfide-bridged) glutathione (GSSG). Labeled methionine, and perhaps cysteine, was found in higher concentrations, while labeled GSSG was found in considerably higher concentrations in the innervated side of the buccal mass. As both sides of the buccal mass were exposed to similar levels of radioactive methionine that had leaked through the Vaseline gap, the higher levels of these small molecules in the innervated side suggest that the molecules diffused down the nerves from the ganglia to buccal muscle. It also suggests that, over the period of these expcriments (2-3 d), a significant proportion of ${ }^{35} \mathrm{~S}$ in methionine could be transferred to cysteine, either free or in GSSG. The rapid diffusion of small molecules down axons has been described previously in Aplysia (Koike and Nagata, 1979; Goldberg and Schwartz, 1980).

\section{Transport of labeled peptides from buccal ganglia to buccal muscles via lateral nerves}

Lateral nerves are those nerves that exit the ganglion from the lateral margin, and include nerves 1, 2, and 3 (Gardner, 1971). Figure 3 summarizes the transport of identified peptides to individual muscles and muscle groups in 5 experiments. In Figure 


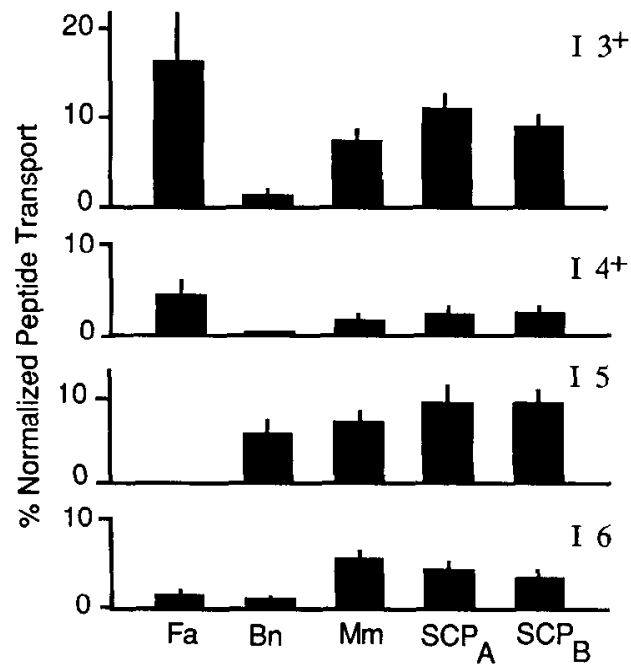

Figure 3. Summary of the transport of 5 neuropeptides from buccal ganglia to buccal muscles via the lateral nerves. These values represent specific concentrations of labeled peptides in extracts from the equivalent of $50 \mathrm{mg}$ tissue and are normalized to the number of residues of methionine in each peptide and as a percentage of the total peptide transport (see text for details). Error bars are SE with $n=5$. See Figure 1 for explanation of muscle designations.

3 , the radioactivity associated with each peptide was corrected to represent transport to an equivalent weight of muscle $(50 \mathrm{mg})$ and for the number of methionine residues in each peptide. $\mathrm{Mm}$ and $\mathrm{SCP}_{\mathrm{B}}$ each have 2 methionine residues as compared to one in each of the other 3 peptides, so the radioactivity in their peaks was divided by 2 . It was necessary to normalize these activity values in each experiment because preparations from different animals showed a wide range of total ${ }^{35} \mathrm{~S}$-methionine incorporation, presumably stemming from differences in endogenous methionine pools or other metabolic factors. For each preparation, the corrected specific activity of each peptide to each muscle was totaled, and the specific activity of any single peptide transported to a muscle was then given as the percentage of this total. When normalized in this fashion, the specific activity of peptides transported to particular muscles was quite reproducible (i.e., Figs. 3, 6).

The pattern of transported peptides is different for each muscle (Fig. 3). Fa was transported primarily to $14+$ and $\mathrm{I} 3+$, in low levels to I6, and in very low levels to I5. Muscle I5 is also referred to as the accessory radula retractor muscle (Cohen et al., 1978). Bn was transported in amounts comparable to those of the other peptides only to I5. With the exception of I4+, the SCPs and Mm were transported to each of the muscles in similar amounts. The low specific activity for peptide transport to I4+ may reflect the fact that this sample included a significant proportion of connective tissue, as well as the $\mathrm{I} 4$ muscle group. Finally, $\mathrm{SCP}_{\mathrm{A}}$ was found in amounts very similar to those of $\mathrm{SCP}_{\mathrm{B}}$ in every muscle. This result was expected from the observations that identified neurons synthesize the $2 \mathrm{SCP}$ s in equimolar concentrations, and that the SCP precursor contains single copies of each SCP (Mahon et al., 1985; Lloyd et al., 1987b). The results of an experiment in which transport via the lateral nerves to muscles $\mathrm{I} 3+$ and $\mathrm{I} 5+$ was analyzed show the procedure used to quantify transport (Figs. 4, 5). As in the cumulative data, this $\mathrm{I} 3+$ muscle receives comparable levels of $\mathrm{Fa}, \mathrm{Mm}$, and the SCPs and much lower amounts of Bn, while this I5 muscle receives comparable amounts of $\mathrm{Mm}$, the SCPs, and $\mathrm{Bn}$,
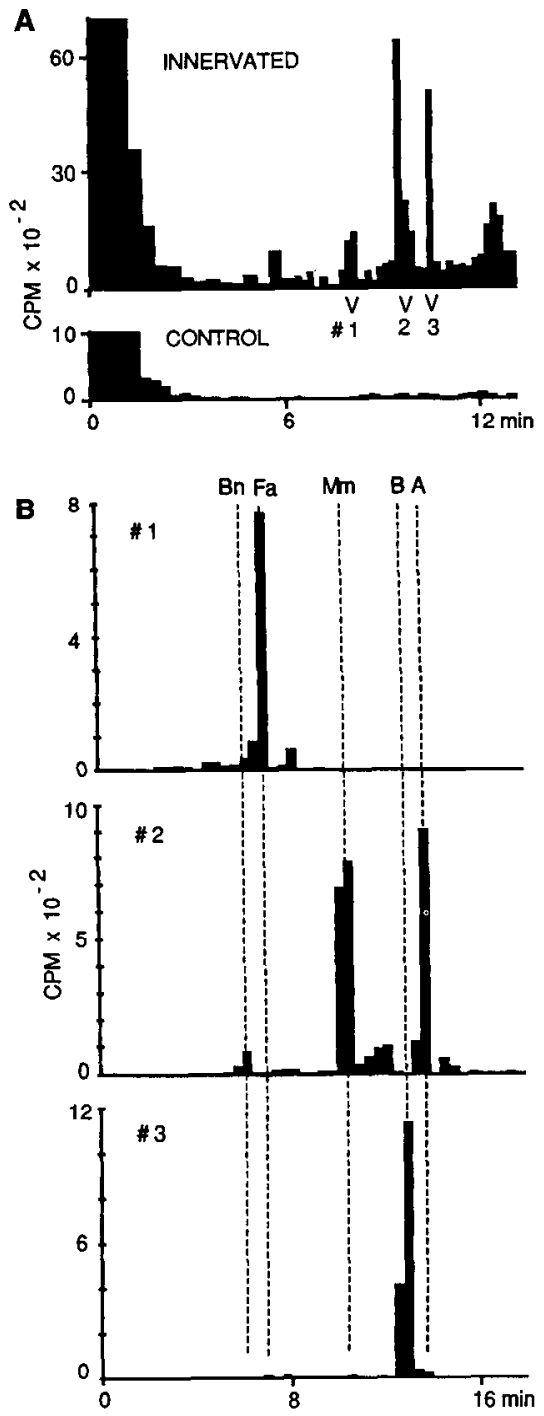

Figure 4. Transport of methionine-labeled peptides from buccal ganglia to muscle $13+$ via the lateral nerves. $A$, HPLC with TFA as counterion of extracts from the innervated and noninnervated (control) $\mathrm{I} 3+$ muscles from the same buccal mass. In this experiment, the axes of the innervated and control sides were scaled to the total number of counts per minute collected in each run. $B$, Aliquots of the samples marked 13 in $A$ were run on HPLC with HFBA as counterion. Retention times of synthetic peptides are indicated by the dashed lines. Sample 1 was primarily $\mathrm{Fa} ; 2$ was $\mathrm{Mm}, \mathrm{SCP}_{\mathrm{A}}$, and a trace of $\mathrm{Bn}, 3$ was nearly all $\mathrm{SCP}_{\mathrm{B}}$. Note that the counts per minute have not been normalized for methionine content: $\mathrm{Mm}$ and $\mathrm{SCP}_{\mathrm{B}}$ have 2 methionine residues to one for the other peptides.

but nearly no Fa. In both Figures 4 and 5, the activity in the peptide peaks was not corrected for the number of methionine residues per peptide. Note that there were no peptide peaks in the control (noninnervated) contralateral muscles.

As mentioned above, these comparisons are based on analyses of $50 \mathrm{mg}$ of tissue or, in the case of smaller muscles, are corrected to the equivalent of $50 \mathrm{mg}$. To compare total transport, the size of the muscle was taken into account. Normalizing the weight of the smallest muscle, I5, to $1.0: \mathrm{I} 2$ was 1.5 ; I3+ was 15.2 ; I6 was 15.3; and I4 + was 23.8-fold larger. Using the normalized weights and the normalized specific transport values (see Fig. 3 ), the percentages of total peptide transport via the lateral nerves were as follows: $\mathrm{Fa}, 30.7 \% ; \mathrm{SCP}_{\mathrm{A}}, 24.2 \%$; $\mathrm{SCP}_{\mathrm{B}}, 21.0 \%$; $\mathrm{Mm}$, 

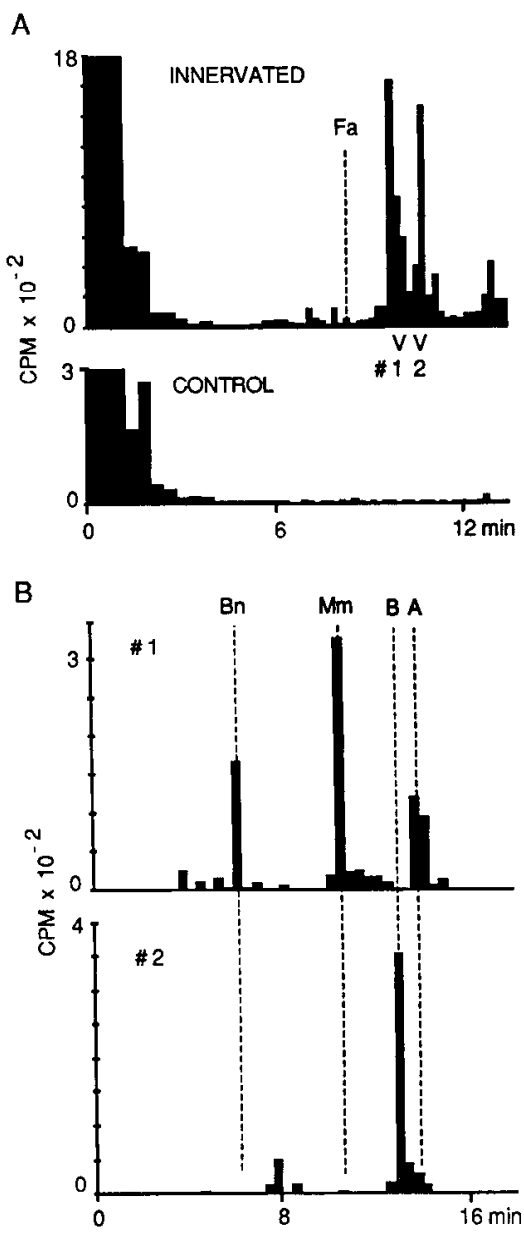

Figure 5. Transport of methionine-labeled peptides from buccal ganglia to muscle I5 via the lateral nerves. $A$, HPLC with TFA as counterion of extracts from the innervated and noninnervated (control) I5 muscles from the same buccal mass. In this experiment, the axes of the innervated and control sides were scaled to the total number of counts per minute collected in each run. $B$, Aliquots of the samples marked 1 and 2 in $A$ were run on HPLC with HFBA as counterion. Retention times of synthetic peptides are indicated by the dashed lines. Sample $l$ was $\mathrm{SCP}_{\mathrm{A}}, \mathrm{Mm}$, and $\mathrm{Bn} ; 2$ was nearly all $\mathrm{SCP}_{\mathrm{B}}$. Note that the counts per minute have not been normalized for methionine content: $\mathrm{Mm}$ and $\mathrm{SCP}_{\mathrm{B}}$ have 2 methionine residues to one for the other peptides.

$20.5 \%$; and $\mathrm{Bn}, 3.6 \%$. These values reflect the fact that the muscle groups in which $\mathrm{Fa}$ was the predominant transported peptide, $\mathrm{I} 3+$ and $\mathrm{I} 4+$, are very large, whereas $\mathrm{I} 5$, the only muscle with transport of Bn comparable to that of the other peptides, is very small.

Other small intrinsic (not identified in Fig. 1) and extrinsic (E2 and E3 in Fig. 1) muscles were also analyzed. No transported peptides were observed; however, many of these muscles weighed only a milligram or less, so moderate levels of transport would not have been detected. In addition, in one of the 5 experiments, $\mathrm{Fa}, \mathrm{Mm}$, and the SCPs, but not $\mathrm{Bn}$, were transported to muscle I2. In the other 4 experiments, no transported peptides were observed in this muscle. We have no explanation for why transport was observed in only a single experiment.

\section{Transport of labeled peptides from buccal ganglia to buccal} muscle via radula nerves

The radula nerve leaves the buccal ganglia from the commissure between the 2 ganglia and immediately enters the muscles of

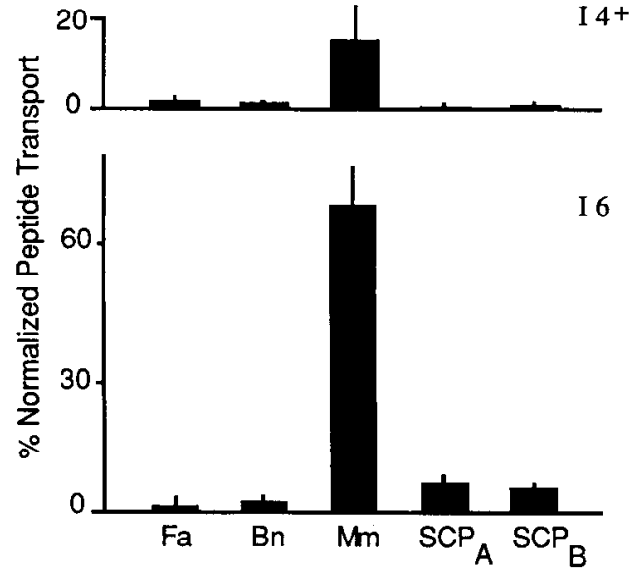

Figure 6. Summary of the transport of 5 neuropeptides from buccal ganglia to buccal muscles via the radula nerves. These values represent specific concentrations of labeled peptides in extracts from the equivalent of $50 \mathrm{mg}$ tissue and are normalized to the number of residues of methionine in each peptide and as a percentage of the total peptide transport (see text for details). No transport to I3+ or I5 was observed in any of the experiments. Error bars are SE with $n=3$. See Figure 1 for explanation of muscle designations.

the buccal mass, where it runs for a few millimeters before dividing into 2 major branches. Each branch innervates one side of the buccal mass. To obtain a sufficient length to run through the Vaseline gap, the nerve was dissected free of the muscle up to its bifurcation, and one branch was severed to provide the noninnervated control side. Even so, the length of free nerve was considerably shorter than that available for the lateral nerves and, consequently, more tension was placed on the radula nerve. Significant transport was observed in 3 of 4 experiments. Presumably, in the onc unsuccessful cxpcriment, transport was disrupted by undue stretching of the radula nerve. The cumulative data from the 3 experiments in which significant transport was observed are shown in Figure 6. Again, when normalized as described above, the nature of the peptide transport was quite reproducible between preparations. The pattern was very different from that observed for the lateral nerves. Peptides were only transported to I4+ and I6. Using the normalized weights and the normalized specific transport values, the percentages of total peptide transport via the radula nerve were as follows: $\mathrm{Mm}, 83.9 \% ; \mathrm{SCP}_{\mathrm{A}}, 6.1 \% ; \mathrm{SCP}_{\mathrm{B}}, 5.1 \%$; Bn 3.1\%; and $\mathrm{Fa}, 1.7 \%$. Thus, $\mathrm{Fa}$, which was transported in the largest quantities by the lateral nerves, was transported in the lowest quantities in the radula nerves.

\section{Quantitative comparison of overall peptide transport between lateral and radula nerves}

A quantitative comparison of transport via the lateral and radula nerves is complicated by the variability we observed within each nerve group. However, a few generalizations can be made. First, the peptide transported in the greatest quantity was certainly $\mathrm{Mm}$ to 16 via the radula nerve. In 3 experiments, total $\mathrm{Mm}$ transport to the whole I6 muscle was $23,805 \pm 12,505 \mathrm{cpm}$ (SE). In comparison, $\mathrm{Mm}$ transport to $\mathrm{I} 6$ via the lateral nerves was $4061 \pm 1844 \mathrm{cpm}(n=5)$, and the predominant peptide transported via the lateral nerves was $\mathrm{Fa}$ to $\mathrm{I} 3+$, at $4987 \pm$ $2764 \mathrm{cpm}(n=5)$. When the number of methionine residues are taken into account, about twice as much $\mathrm{Mm}$ was transported to I6 via the radula nerves as was $\mathrm{Fa}$ to $\mathrm{I} 3+$ via the lateral nerves. The difference is actually more dramatic than 
this, since this is a comparison of a single radula nerve with 3 lateral nerves.

\section{Transport of labeled peptides from cerebral ganglia}

The other central ganglia that play a role in the consummatory (biting) phase of feeding behavior in Aplysia are the cerebral ganglia (e.g., Kupfermann, 1974). In addition, neurons in the cerebral ganglia provide the major serotonergic modulatory innervation of buccal muscles (Weiss et al., 1978). Therefore, peptide transport from the cerebral ganglia to the buccal ganglia and buccal muscles was also analyzed. No transport of labeled peptides to any of the buccal muscles was observed in 3 experiments. However, in each of these experiments, significant transport of $\mathrm{Mm}$ to the buccal ganglia was observed (Fig. 7). Very small amounts of $\mathrm{Bn}$ and $\mathrm{Fa}$, and no measurable $\mathrm{SCP}$ or $\mathrm{SCP}_{\mathrm{B}}$, were observed to be transported from the cerebral to buccal ganglia. There are several reasons to believe that the absence of transport from the cerebral ganglia to buccal muscle was not simply a reflection of the increased transport distance. First, significant transport of neuropeptides from the abdominal ganglia to the cerebral ganglia has been consistently observed within the same time periods used in this study (P. E. Lloyd, unpublished observations). The distance from the abdominal to cerebral ganglia is severalfold greater than that from the cerebral ganglia to the most distant buccal muscles. Second, substantial transport of $\mathrm{Mm}$ to the buccal ganglia was observed in each of 3 experiments. The number of counts of $\mathrm{Mm}$ in the buccal ganglia was $6513 \pm 4074(\mathrm{SE})$. Transport of even a few percent of this to buccal muscles would have been noted. Finally, in 2 experiments, the lateral and radula nerves that lead from the buccal ganglia to the muscles were pooled, extracted, and analyzed by HPLC. Again, no labeled peptides were detected. The fact that $\mathrm{Mm}$ is transported to the huccal ganglia and no further suggests that this peptide is likely to have important central actions in these ganglia.

\section{Discussion}

We have identified neuropeptides that were transported by fast axonal transport from the buccal ganglia to buccal muscles. Selective fast axonal transport of conventional neurotransmitters has been previously observed in Aplysia (reviewed in Schwartz, 1979). The major transported peptides were $\mathrm{Fa}, \mathrm{Bn}$, $\mathrm{Mm}$, and the 2 SCPs. These results support the proposition that each of these peptides functions as a neuromodulator at the synapses between buccal motor neurons at their target muscles. Each of the peptides has previously been shown to be present in the buccal ganglia and buccal muscle of Aplysia, and to modulate the efficacy of neuromuscular synaptic transmission at buccal muscle (Lloyd et al., 1985, 1987a; Richmond et al., 1986; Cropper et al., 1987a-c; and D. P. Lotshaw and P. E. Lloyd, unpublished observations). $\mathrm{Bn}$ and $\mathrm{Mm}$ were identified and sequenced very recently, so there is little additional information concerning their roles in Aplysia nervous tissue. There is evidence that the SCPs play major roles in the regulation of all aspects of feeding behavior (Lloyd, 1986). These peptides are found in 10-fold higher concentrations in the buccal ganglia than in other regions of the central nervous system (Lloyd et al., 1985). They appear to be involved in the control of the central pattern generator for feeding in the buccal ganglia of Aplysia (Sossin et al., 1987) and other gastropods (Murphy et al., 1985; Willows et al., 1988). In addition, 2 identified SCP-containing neurons regulate gut motility during feeding (Lloyd and Willows,
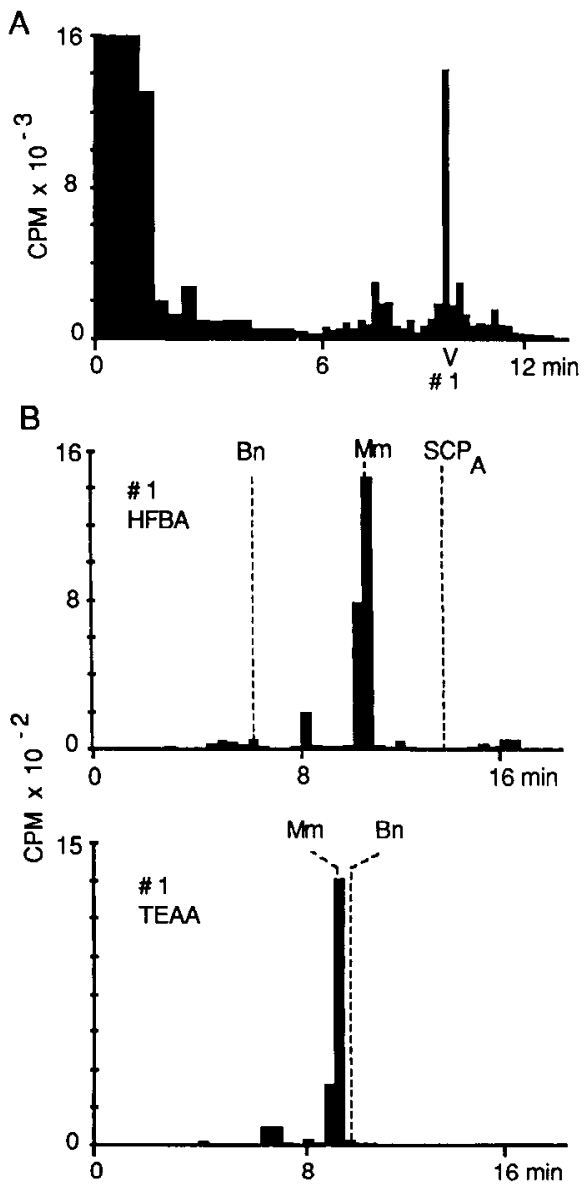

Figure 7. Transport of methionine-labeled peptides from cerebral ganglia to buccal ganglia via the cerebrobuccal connectives (CBCs). $A$, HPLC with TFA as counterion of extracts from the buccal ganglia. In this experiment, both CBCs were left intact, so there is no control; however, the profile of incorporation, when the buccal ganglia themselves are incubated with labeled methionine, is very different from that seen here (Lloyd et al., 1987b). $B$, In the upper profile, aliquots of samples $I$ in $A$ were run on HPLC with HFBA as counterion. Retention times of synthetic peptides are indicated by the dashed lines. Sample $I$ was nearly all $\mathrm{Mm}$, with a trace of $\mathrm{Bn}$ and no $\mathrm{SCP}_{\mathrm{A}}$. In the lower profile, aliquots of samples 1 in $A$ were run on HPLC using TEAA buffer at $\mathrm{pH} 5.5$. Note that this buffer reverses the relative retention times of $\mathrm{Mm}$ and $\mathrm{Bn}$, but that the labeled peak continues to coelute precisely with $\mathrm{Mm}$. The combination of these 3 procedures confirms that $\mathrm{Mm}$ is the predominant methionine-containing peptide transported from the cerebral ganglia to the buccal ganglia.

1988; Lloyd et al., 1988). These neurons contain the SCPs in dense-core vesicles and release these peptides in an activity- and calcium-dependent manner, indicating that the SCPs are indeed transmitters (Lloyd et al., 1986; Reed et al., 1988). FMRFamide has also been localized to dense-core vesicles (Kreiner et al., 1986), and FMRFamide or FMRFamide-like substances have been implicated in the modulation of the contractile activity of gill muscles in Aplysia (Weiss et al., 1984). Finally, Fa and the SCPs have been shown to modulate central synapses between sensory and motor neurons in the abdominal ganglia of Aplysia (Abrams et al., 1984; Belardetti et al., 1987).

Several conclusions can be drawn from the present data. $\mathrm{Mm}$ was the predominant peptide transported to buccal muscle, which occurred primarily via the radula nerves. The overall quantity of transport to the whole buccal mass was similar for $\mathrm{Fa}$ and the SCPs, but Bn was transported at significantly lower levels. 
This reflects the finding that the only muscle to receive quantities of Bn comparable to those of the other peptides, I5, was the smallest of the muscles or muscle groups in which transport was consistently observed. Different complements of peptides were transported to different muscles. For example, very low amounts of Fa were transported to I5, whereas Fa was the predominant peptide transported to $\mathrm{I} 3+$. In addition, different complements of peptides were transported down different nerve groups. Similar quantities of $\mathrm{Fa}, \mathrm{Mm}$, and the SCPs, and much smaller amounts of $\mathrm{Bn}$, were transported by the lateral nerves. $\mathrm{Mm}$ was the predominant peptide transported by the radula nerves. The differential transport of these peptides to individual buccal muscles suggests that their modulatory actions are tailored to particular muscles. This has important implications for functional studies of the physiological roles of these peptides.

No methionine-containing peptides were transported from the ccrcbral ganglia to buccal muscles. This was somewhat surprising in light of the finding that the neurons that provide the serotonergic modulation of the buccal muscles are located in these ganglia. However, large quantities of $\mathrm{Mm}$ were transported from the cerebral ganglia to the buccal ganglia. In Aplysia, neurons in the cerebral ganglia are known to regulate patterned motor output from the buccal ganglia (e.g., Weiss et al., 1978; Rosen et al., 1987). The present results suggest that $\mathrm{Mm}$ may play an important role in this regulation.

Although the buccal neurons that synthesize the peptides were not identified in this study, it is likely that a significant proportion of the transported peptides was synthesized by motor neurons. Motor neurons have been shown to synthesize each of these peptides (Cropper et al., 1987a-c; Lloyd et al., 1987a; and D. P. Lotshaw and P. E. Lloyd, unpublished observations). Indeed, in the case of 15 , the cholinergic motor neurons that innervate this muscle and synthesizc cach of the pcptides transported to it have been identified. Motor neuron B15 makes the SCPs and Bn, while B16 synthesizes $\mathrm{Mm}$. These are the 2 major motor neurons that innervate this muscle (Cohen et al., 1978). This raises the possibility that much of the observed transport to other muscles is also carried out by motor neurons.

These results do not rule out the possibility that other methionine-containing neuropeptides are also transported to buccal muscles. Specifically, it is likely that moderate levels of transport to a small muscle bundle within a large muscle group would not have been noticed. Peaks with low activity were observed in many experiments, but it has not been possible to determine whether these were fragments of the known transported peptides, peptides synthesized in the muscles themselves, or neuropeptides transported from the buccal ganglia at low levels.

This procedure for measuring transport is likely to have general applications. Indeed, a similar procedure has been used to measure interganglionic transport in Aplysia (P. E. Lloyd, unpublished observations). The use of HPLC permits the identification of peptides against high backgrounds of unincorporated radiolabel. However, experience with labeling Aplysia ganglia suggests that this procedure may be less successful when radioactive amino acids other than methionine, or perhaps cysteine, are used. This is due to a combination of high specific activity and what appear to be low endogenous pools of the sulfurcontaining amino acids.

\section{References}

Abrams, T. W., V. F. Castellucci, J. S. Camardo, E. R. Kandel, and P. E. Lloyd (1984) Two endogenous neuropeptides modulate the gill and siphon withdrawal reflex in Aplysia by presynaptic facilitation involving cAMP dependent closure of a serotonin-sensitive potassium channel. Proc. Natl. Acad. Sci. USA 81: 7956-7960.

Belardetti, F., E. R. Kandel, and S. A. Siegelbaum (1987) Neuronal inhibition by the peptide FMRFamide involves opening of the $\mathrm{S} \mathrm{K}^{+}$ channels. Nature 325: 153-156.

Cohen, J. L., K. R. Weiss, and I. Kupfermann (1978) Motor control of buccal muscles in Aplysia. J. Neurophysiol. 41: 157-180.

Cropper, E. C., P. E. Lloyd, W. Reed, R. Tenenbaum, I. Kupfermann, and K. R. Weiss (1987a) Multiple neuropeptides in cholinergic motor neurons of Aplysia: Evidence for modulation intrinsic to the motor circuit. Proc. Natl. Acad. Sci. USA 84: 3486-3490.

Cropper, E. C., R. Tenenbaum, M. A. Gawinowicz Kolks, I. Kupfermann, and K. R. Weiss (1987b) Myomodulin: A bioactive neuropeptide present in an identified cholinergic buccal motor neuron of Aplysia. Proc. Natl. Acad. Sci. USA 84: 5483-5486.

Cropper, E. C., R. Tenenbaum, I. Kupfermann, and K. R. Weiss (1987c) Buccalin: A novel modulatory neuropeptide colocalized to the SCPcontaining cholinergic motoneuron B15 of Aplysia. Soc. Neurosci. Abstr. 13: 37.

Gardner, D. (1971) Bilateral symmetry and interneuron organization in the buccal ganglia of Aplysia. Science 173: 550-553.

Goldberg, D. J., and J. H. Schwartz (1980) Fast axonal transport of foreign transmitters in an identified serotonergic neurone of Aplysia californica. J. Physiol. (Lond.) 307: 259-272.

Howells, H. H. (1942) The structure and function of the alimentary canal of Aplysia punctata. Quart. J. Microscop. Sci. 83: 357-397.

Koike, H., and Y. Nagata (1979) Intra-axonal transport of $\left[{ }^{3} \mathrm{H}\right]$ acetylcholine and $\left[{ }^{3} \mathrm{H}\right]$ gamma-aminobutyric acid in a neurone of Aplysia. J. Physiol. (Lond.) 295: 397-417.

Kreiner, T., W. Sossin, and R. H. Scheller (1986) Localization of Aplysia neurosecretory peptides to multiple populations of dense core vesicles. J. Cell Biol. 102: 769-782.

Kupfermann, I. (1974) Dissociation of the appetitive and consummatory phases of feeding in Aplysia: A lesion study. Behav. Biol. 10: 89-97.

Lloyd, P. E. (1986) The small cardioactive peptides: A class of modulatory neuropeptides in Aplysia. Trends Neurosci. 9: 428-431.

Lloyd, P. E., and A. O. D. Willows (1988) Multiple transmitter neurons in Tritonia: II. Control of gut motility. J. Neurobiol. (in press).

Lloyd, P. E., I. Kupfermann, and K. R. Weiss (1984) Evidence for parallel actions of a molluscan peptide $\left(\mathrm{SCP}_{\mathrm{B}}\right)$ and serotonin in mediating arousal in Aplysia. Proc. Natl. Acad. Sci. USA 81: 2934-2937.

Lloyd, P. E., A. C. Mahon, I. Kupfermann, J. L. Cohen, R. H. Scheller, and K. R. Weiss (1985) Biochemical and immunocytological localization of molluscan small cardioactive peptides (SCPs) in the nervous system of Aplysia californica. J. Neurosci. 5: 1851-1861.

Lloyd, P. E., S. Schacher, I. Kupfermann, and K. R. Weiss (1986) Calcium-dependent release of neuropeptides during intracellular stimulation of single identified Aplysia neurons in culture. Proc. Natl. Acad. Sci. USA 83: 9794-9798.

Lloyd, P. E., M. Frankfurt, P. Stevens, I. Kupfermann, and K. R. Weiss (1987a) Biochemical and immunocytological localization of the neuropeptides $\mathrm{SCP}_{\mathrm{A}}, \mathrm{SCP}_{\mathrm{B}}$, and $\mathrm{FMRFamide}$ to neurons involved in the regulation of feeding in Aplysia. J. Neurosci. 7: 1123-1132.

Lloyd, P. E., I. Kupfermann, and K. R. Weiss (1987b) The sequence of small cardioactive peptide A: A second member of a class of neuropeptides in Aplysia. Peptides 8: 179-184.

Lloyd, P. E., I. Kupfermann, and K. R. Weiss (1988) Central peptidergic neurons regulate gut motility in Aplysia. J. Neurophysiol. 59: 1613-1626.

Mahon, A. C., P. E. Lloyd, K. R. Weiss, I. Kupfermann, and R. H. Scheller (1985) The small cardioactive peptides A and B of Aplysia are derived from a common precursor molecule. Proc. Natl. Acad. Sci. USA 82: 3925-3929.

Morris, H. R., M. Panico, A. Karplus, P. E. Lloyd, and B. Riniker (1982) Elucidation by FAB-MS of the structure of a new cardioactive peptide from Aplysia. Nature 300: 643-645.

Murphy, A. D., K. Lukowiak, and W. K. Stell (1985) Peptidergic modulation of patterned motor activity in identified neurons in Helisoma. Proc. Natl. Acad. Sci. USA 82: 7140-7144.

Price, D. A., and M. J. Greenberg (1977) Structure of a molluscan cardioexcitatory neuropeptide. Science 197: 670-671.

Reed, W., K. R. Weiss, P. E. Lloyd, I. Kupfermann, M. Chen, and C. H. Bailey (1988) Immunolocalization of the molluscan small car- 
dioactive peptides A and B to the protein secretory pathway in identified neurons of Aplysia californica. J. Comp. Neurol. (in press).

Richmond, J. E., A. G. M. Bulloch, and K. Lukowiak (1986) Peptidergic modulation of a neuromuscular junction in Aplysia: Bioactivity and immunocytochemistry. 370: 159-164.

Rosen, S. C., M. W. Miller, K. R. Weiss, and I. Kupfermann (1987) Control of buccal motor neurons in Aplysia by identified neurons in the cerebral ganglia. Soc. Neurosci. Abstr. 13: 1061.

Scheller, R. H., R.-R. Kaldany, T. Kreiner, A. C. Mahon, J. R. Nambu, M. Schaefer, and R. Taussig (1984) Neuropeptides: Mediators of behavior in Aplysia. Science 225: 1300-1308.

Schwartz, J. H. (1979) Axonal transport: Components, mechanisms, and specificity. Annu. Rev. Neurosci. 2: 467-504.

Sossin, W. S., M. D. Kirk, and R. H. Scheller (1987) Peptidergic modulation of neuronal circuitry controlling feeding in Aplysia. J. Neurosci. 7: 671-681.

Weiss, K. R., J. Cohen, and I. Kupfermann (1978) Modulatory control of buccal musculature by a serotonergic neuron (metacerebral cell) in Aplysia. J. Neurophysiol. 41: 181-203.

Weiss, K. R., P. E. Lloyd, E. C. Cropper, M. Frankfurt, and I. Kupfermann (1986) FMRFamide is present in the ARC muscle of Aplysia and depresses its contractions. Soc. Neurosci. Abstr. 12: 947.

Weiss, S. J., J. I. Goldberg, K. S. Chohan, W. K. Stell, G. I. Drummond, and K. Lukowiak (1984) Evidence for FMRFamide as a neurotransmitter in the gill of Aplysia californica. J. Neurosci. 4: 1994-2000.

Willows, A. O. D., P. E. Lloyd, and B. P. Masinovsky (1988) Identified multiple transmitter neurons in Tritonia: III. Modulation of the central pattern generator controlling feeding. J. Neurobiol. 19: 69-86. 